\title{
KARAKTERISTIK SOSIAL EKONOMI MASYARAKAT PERAMBAH DAN PERUBAHAN PENUTUPAN LAHAN KAWASAN HUTAN PRODUKSI AIR SAMBAT REG 84 DI KABUPATEN KAUR PROPINSI BENGKULU
}

\author{
Arif Budiman ${ }^{1)}$, Gunggung Senoaji ${ }^{2)}$, Enggar Apriyanto ${ }^{2)}$ \\ ${ }^{1)}$ Dinas Tenaga Kerja dan Transmigrasi Kabupaten Kaur \\ 2) Jurusan Kehutanan Fakultas Pertanian UNIB
}

\begin{abstract}
ABSTRAK
Masyarakat yang sudah lama beraktifitas dan bermukim di dalam Kawasan Hutan Produksi Air Sambat Reg. 84 Kecamatan Maje dan Kaur Selatan Kabupaten Kaur telah mendesak kawasan Hutan Produksi tersebut menjadi lahan garapan untuk berkebun dan pemukiman. Tujuan Penelitian ini untuk mengetahui karakteristik sosial ekonomi masyarakat perambah di Kawasan Hutan Produksi Air Sambat Reg. 84, mengetahui klasifikasi tutupan lahan di Kawasan Hutan Produksi Air Sambat Reg. 84, mengetahui perubahan tutupan lahan pada Kawasan Hutan Produksi Air Sambat Reg. 84 dan merumuskan Strategi Pengelolaan Hutan di Kawasan Hutan Produksi Air Sambat Reg. 84. Metode penelitian menggunakan analisis deskriptif kualitatif untuk karakteristik sosial ekonomi perambah dan laju perubahan tutupan lahan menggunakan analisis spasial (Sistem Informasi Geografi). Hasil penelitian menunjukkan bahwa menunjukkan bahwa umur perambah di Hutan Produksi Air Sambat merupakan kategori umur produktif dengan pendidikan yang cukup rendah. Sebagaian besar jumlah anggota keluarga perambah tersebar pada keluarga kecil (4-5 orang), daerah asal perambah $55.50 \%$ berasal dari desa-desa tidak sekitar hutan lindung, asal lahan rambahan $57.29 \%$ diperoleh dengan cara membuka lahan sendiri, dengan motivasi merambah $46.88 \%$ dilatar belakangi oleh faktor ekonomi. Sebagian besar perambah juga memiliki pekerjaan selain dari mengusahakan lahan di kawasan hutan yaitu buruh harian, buruh tani dan berdagang, pengumpul, ojek dan lain sebagainya. Pendapatan total rumah tangga perambah dari lahan rambahan rata-rata Rp. 11.607.812,50/tahun. Jika dilihat dari tingkat kesejahteraan rata-rata perambah berada pada kategori cukup sejahtera. Laju perubahan tutupan lahan yang mengalami peningkatan luas wilayah dalam jumlah yang paling besar adalah pertanian lahan kering campur. Tutupan lahan pertanian lahan kering campur mengalami peningkatan pada tahun 2015 sebesar 1.264,55 hektar atau 264.55 \% lebih luas dibandingkan dengan tahun 2009. Sedangkan tutupan lahan hutan sekunder mengalami penurunan luas wilayah sebesar 1.268,80 hektar atau 35.36\% dari luas tahun 2009. Adapun Strategi pengelolaan yang sesuai di Hutan Produksi Air Sambat adalah Perhutanan Sosial melalui Program Hutan kemasyarakatan seluas \pm 963 Ha dan untuk kawasan permukiman melalui program Tanah Obyek Reforma Agraria seluas $\pm 90,25 \mathrm{Ha}$.
\end{abstract}

Kata Kunci: Hutan Produksi, Perambahan, Tutupan Lahan, Sosial ekonomi, Perhutanan sosial.

\section{PENDAHULUAN}

Hutan sebagai sumberdaya alam (SDA) memiliki multi fungsi yang sangat penting dari kehidupan manusia, terutama secara global sebagai paru-paru dunia, karena dapat mengurangi polusi udara, penyerap karbon (CO2) dan menghasilkan oksigen (O2), tajuk pepohonan yang lebat mampu 
menahan laju kecepatan air hujan sehingga tidak menyebabkan kerusakan tanah serta untuk kesejahteraan masyarakat lokal yang ada di sekitarnya. Disisi lain upaya pelestarian hutan saat ini tidak dapat dipisahkan dengan partisipasi masyarakat di sekitar hutan. Tantangan yang dihadapi saat ini sebagian besar hutan dalam kondisi terdegradasi yang menyebabkan hutan tidak dapat berfungsi sebagaimana peruntukannya dan menyebabkan terjadi lahan kritis. Kawasan Hutan Produksi merupakan kawasan hutan yang dimanfaatkan untuk memproduksi hasil hutan, yang bisa dieksploitasi hasil hutannya dengan cara tebang pilih maupun tebang habis. Hutan Produksi biasanya berupa kawasan hutan yang memiliki kelerengan landai, tanah yang rendah erosi dan memiliki curah hujan yang kecil. Faktor-faktor kelerengan, erosi dan curah hujan tersebut ditentukan dengan cara menghitung indeksnya berdasarkan metode skoring. Areal hutan yang ditetapkan sebagai Hutan Produksi harus memiliki skor dibawah 125, dan areal tersebut tidak termasuk ke dalam kawasan lindung.

Kawasan Hutan Produksi Air Sambat Reg.84 ditetapkan oleh Pemerintah sebagai kawasan hutan dengan fungsi produksi tetap melalui Keputusan Menteri Kehutanan dan Perkebunan Nomor : 487/KPTS-II/1998 tanggal 27 Februari 1998 tentang Penetapan Kelompok Hutan Produksi Air Sambat Reg. 84 Seluas 1.938,00 (seribu Sembilan ratus tiga puluh delapan) Hektar yang Terletak di Daerah Tingkat II Bengkulu Selatan, Propinsi DATI 1 Bengkulu, Sebagai Kawasan Hutan Dengan Fungsi Hutan Produksi Tetap. Kawasan Hutan ini sudah ditata batas (temu gelang) berdasarkan Berita Acara Tata Batas tanggal 19 Mei 1986, tanggal 15 Desember 1992 dan Berita Acara Tata Batas tanggal 18 Maret 1995. Secara administratif Kawasan Hutan Produksi Air Sambat Reg. 84 berada di
Kecamatan Maje dan Kaur Selatan Kabupaten Kaur Provinsi Bengkulu. Berdasarkan Peta Indikatif dan Areal Perhutanan Sosial Revisi I yang dikeluarkan oleh Kementerian Lingkungan Hidup dan Kehutanan melalui Surat Keputusan Menteri Lingkungan Hidup dan Kehutanan Repiblik Indonesia Nomor : SK.4865/MENLHK-

PKTL/REN/PLA.0/9/2017 tanggal 25 September 2017 tentang Peta Indikatif dan Areal Perhutanan Sosial (Revisi I), Kawasan Hutan Produksi Air Sambat Reg. 84 ditetapkan sebagai lokasi indikatif arahan perhutanan sosial (PIAPS Lembar 0911).

Tujuan penelitian ini adalah untuk : 1 . Mengetahui karakteristik sosial ekonomi masyarakat perambah di Kawasan Hutan Produksi Air Sambat Reg. 84, 2. Menelaah klasifikasi tutupan lahan di Kawasan Hutan Produksi Air Sambat Reg. 84, 3. Mengetahui faktor yang berpengaruh terhadap perubahan tutupan lahan pada Kawasan Hutan Produksi Air Sambat Reg. 84, dan 4. Merumuskan Strategi yang tepat dalam Pengelolaan Hutan di Kawasan Hutan Produksi Air Sambat Reg. 84.

\section{METODE PENELITIAN}

\section{Lokasi Penelitian}

Penelitian ini dilaksanakan di Kawasan Hutan Produksi Air Sambat Reg. 84 Kecamatan Maje dan Kaur Selatan Kabupaten Kaur Propinsi Bengkulu.

\section{Teknik Pengumpulan Data}

1. Data Sosial ekonomi perambah di kumpulkan dengan teknik wawancara yaitu pengumpulan data dengan cara bertanya langsung kepada responden dengan menggunakan kuisioner yang bertujuan untuk memperoleh informasi yang relevan serta teknik observasi yaitu metode perolehan informasi yang mengandalkan pengamatan langsung agar lebih mengetahui keadaan umum

Volume 7 Nomor 2, Agustus 2018 
perambah hutan yang dijadiakn objek penelitian.

2. Data perubahan tutupan lahan dikumpulkan dengan cara analisis spasial. Data yang digunakan adalah data spasial yaitu peta tutupan lahan pada Hutan Produksi Air Sambat Reg. 84 tahun 1990, 2010 dan 2016.

3. Data biofisik kawasan yaitu keragaman jenis tanaman/vegetasi yang ditanam di lahan rambahan dilakukan dengan teknik observasi di lapangan dengan metode membuat plot dengan ukuran $20 \mathrm{~m} \times 20 \mathrm{~m}$ sebanyak 3 plot pada masing-masing talang yang diambil secara acak. Sementara itu untuk kelerengan lahan digunakan peta kelerengan dan observasi ke lapangan.

\section{Analisa Data}

1. Karakteristik sosial ekonomi perambah, menggunakan analisis deskriptif kualitatif, merupakan metode berupa uraian-uraian kalimat yang tidak menggunakan perhitungan angka-angka.

2. Laju perubahan tutupan lahan menggunakan analisis spasial (Sistem Informasi Geografi) dengan cara dengan membandingkan peta tutupan lahan tahun 1990, 2010 dan 2016. Hal ini dilakukan untuk mengetahui laju perubahan tutupan lahan yang terjadi pada tahun 1990, 2010 dan 2016.

\section{HASIL DAN PEMBAHASAN}

\section{Perubahan Penutupan Lahan Kawasan Hutan Produksi Air Sambat}

Tutupan lahan yang ada di Hutan Produksi Air Sambat berdasarkan survei lapangan di kelompokkan menjadi 6 kategori yaitu : hutan sekunder, pertanian lahan kering campur, tubuh air, lahan kosong, sawah dan pemukiman.

Tabel 1. Tutupan lahan di Hutan Produksi Air Sambat Tahun 1990

\begin{tabular}{lcc}
\hline \multicolumn{1}{c}{ Tutupan lahan } & Ha & Jumlah \\
\cline { 3 - 3 } & & Persentase (\%) \\
\hline $\begin{array}{l}\text { Hutan sekunder } \\
\text { Pertanian lahan kering campur }\end{array}$ & $2.069,39 \mathrm{Ha}$ & 100 \\
Hutan Primer & & \\
Tegalan/Ladang & & \\
\hline Jumlah & $2.069,39 \mathrm{Ha}$ & 100 \\
\hline
\end{tabular}

Tabel 2. Tutupan lahan di Hutan Produksi Air Sambat tahun 2010

\begin{tabular}{lccc}
\hline \multicolumn{1}{c}{ Tutupan lahan } & & Jumlah & \\
\cline { 2 - 2 } & & Ha & Persentase $(\%)$ \\
\hline Hutan sekunder & & 715,279 & 34,56 \\
Pertanian lahan kering campur & 334,917 & 16,18 \\
Hutan Primer & 602,501 & 29,11 \\
Tegalan/Ladang & 416,694 & 20,14 \\
\hline \multicolumn{1}{c}{ Jumlah } & $2.069,39$ & 100 \\
\hline
\end{tabular}


Tabel 3. Tutupan lahan di Hutan Produksi Air Sambat tahun 2016

\begin{tabular}{lcc}
\hline \multicolumn{1}{c}{ Tutupan lahan } & Jumlah & \\
& Ha & Persentase $(\%)$ \\
\hline Hutan lahan kering sekunder / bekas te- & 187,09 & 9,04 \\
Semak belukar & 211,85 & 10,24 \\
Pertanian lahan kering campur semak & $1.580,20$ & 76,36 \\
\multirow{2}{*}{ Pemukiman } & 90,25 & 4,36 \\
\hline \multicolumn{1}{c}{ Jumlah } & $2.069,39$ & 100 \\
\hline
\end{tabular}

Sumber : Interpretasi citra landsat Tahun 1990, 2010 dan 2016, Data diolah, 2018

Adapun faktor-faktor yang mempengaruhi perubahan tutupan lahan di Hutan Produksi Air Sambat di tinjau dari aspek sosial ekonomi masyarakat perambah adalah: Laju pertumbuhan penduduk dan penduduk miskin, adanya Izin Hak Pengelolaan Hutan PT. Bengkulutama Raya Timbre dan Izin Usaha Hutan Tanaman Rakyat (HTR) serta Kurangnya Pengawasan dari aparat terkait.

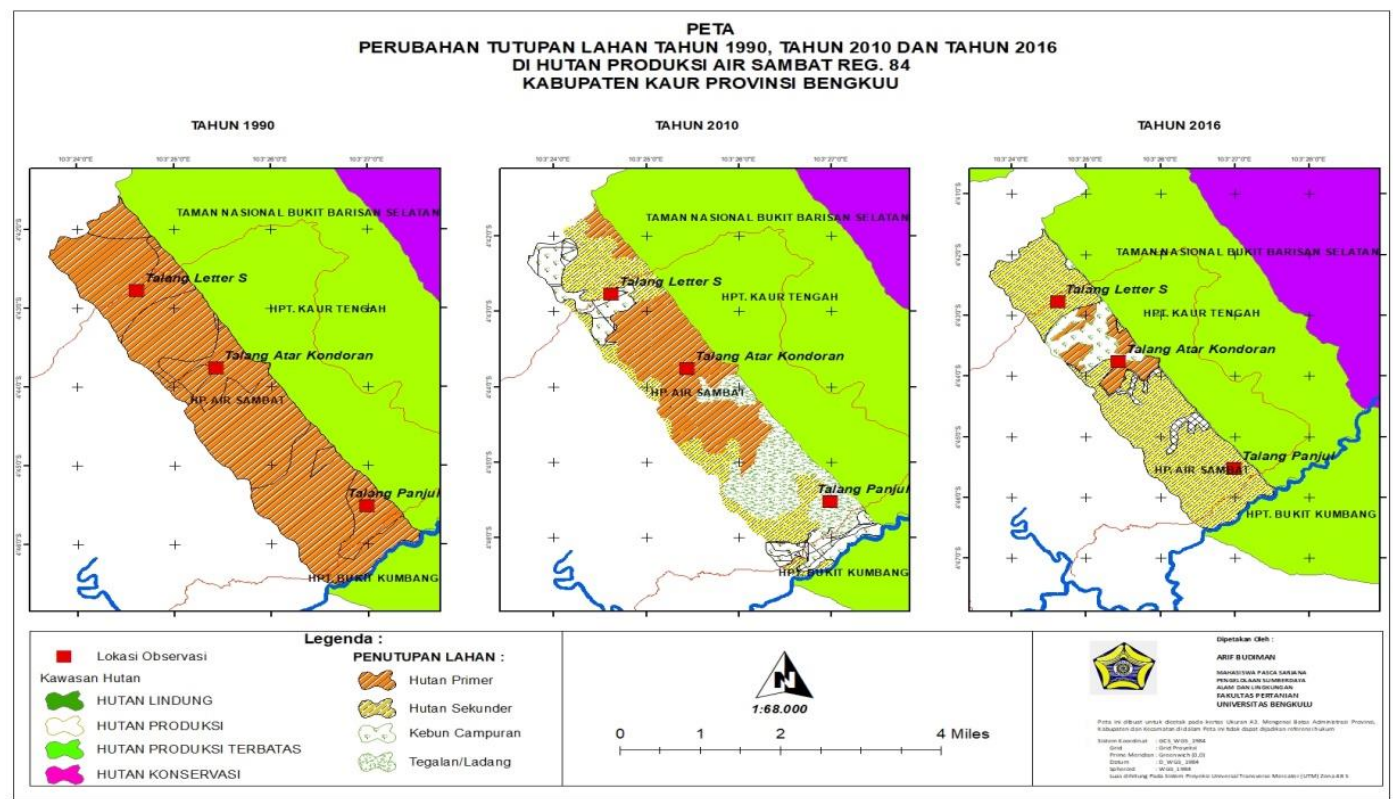

Gambar 1. Peta perubahan tutupan lahan tahun 1990, 2010 dan tahun 2016 di Hutan Produksi Air Sambat

\section{Kondisi Biofisik Kawasan}

Berdasarkan observasi di lapangan diketahui jenis vegetasi atau tanaman pada Hutan Produksi Air Sambat didominasi oleh tanaman kopi, karet, kakao dan jengkol. Hal ini sejalan dengan tipikal Masyarakat perambah umumnya seperti hasil penelitian Senoaji, 2009 menyebutkan bahwa di hutan lindung Bukit Daun Kabupaten Rejang Lebong masyarakat perambah mengalihfungsikan lahan hutan menjadi lahan perkebunan kopi, kakao dan karet.

Volume 7 Nomor 2, Agustus 2018 


\section{Karakteristik Sosial Perambah}

Berdasarkan hasil observasi lapangan terhadap 56 responden (Kepala Keluarga) yang melakukan perambahan di dalam kawasan Hutan Produksi Air Sambat diketahui hasil sebagai mana terdapat didalam table-tabel dibawah ini:

Tabel 4. Daerah Asal Perambah di HP. Air Sambat Reg. 84

\begin{tabular}{|c|c|c|}
\hline Pelaku Perambah & $\begin{array}{l}\text { Jumlah perambah } \\
\text { (KK) }\end{array}$ & $\begin{array}{l}\text { Persentase per- } \\
\text { ambah }(\%)\end{array}$ \\
\hline A. Masyarakat sekitar Hutan Produksi & 16 & 28,50 \\
\hline Kecamatan Kaur Selatan & 9 & 16,07 \\
\hline - Desa Jembatan Dua & 3 & 5,36 \\
\hline - Desa Tanjung Besar & 2 & \\
\hline - Desa Gedung Sako & 1 & 3,57 \\
\hline - Desa Padang Genteng & 2 & \\
\hline - Desa Padang Petron & 1 & 1,79 \\
\hline Kecamatan Maje & 7 & 12,50 \\
\hline - Desa Kedataran & 2 & 3,57 \\
\hline - Desa Tanjung Ganti & 2 & \\
\hline - Desa Penyandingan & 3 & 3,57 \\
\hline $\begin{array}{l}\text { B. Masyarakat yang berasal bukan dari sekitar Hu- } \\
\tan \text { Produksi }\end{array}$ & 40 & 71,43 \\
\hline Kabupaten Kaur & 16 & 28,57 \\
\hline - Kecamatan Kelam Tengah & 3 & \\
\hline - Kecamatan Padang Guci Hulu & 4 & 5,36 \\
\hline - Kecamatan Lungkang Kule & 7 & \\
\hline - Kecamatan Nasal & 2 & 7,14 \\
\hline Diluar Kabupaten Kaur & 24 & 1250 \\
\hline - Provinsi Lampung & 20 & 12,50 \\
\hline - $\quad$ Provinsi Sumatera Selatan & 4 & 357 \\
\hline Jumlah $(\mathrm{A}+\mathrm{B})$ & 56 & 100 \\
\hline
\end{tabular}

Tabel 5. Motivasi Merambah di dalam Kawasan HP. Air Sambat

\begin{tabular}{clcc}
\hline No & Motivasi Perambah & $\begin{array}{c}\text { Jumlah Perambah } \\
(\mathrm{KK})\end{array}$ & $\begin{array}{c}\text { Persentase } \\
\text { perambah }(\%)\end{array}$ \\
\hline 1. & Tuntutan ekonomi & 25 & 45,45 \\
2. & Lahan rambahan subur & 5 & 9,09 \\
3. & Lahan pertanian kurang & 15 & 27,27 \\
4. & Adanya HPH dan Program HTR & 10 & 18,18 \\
\hline & Jumlah & 56 & 100 \\
\hline
\end{tabular}


Kondisi Ekonomi Perambah Jenis Pekerjaan Sampingan Perambah

Berdasarkan hasil observasi di lapangan masyarakat perambah dominan memiliki mata pencaharin dari pertanian. Pekerjaan utama yang di lakukan adalah mengerjakan lahan/ kebun yang diusahakan di dalam kawasan maupun yang ada di luar kawasan hutan. Pekerjaan sampingan yang dimiliki masyarakat perambah terdiri dari buruh tani, berdagang, ojek, pembuat gula aren dan tidak memiliki pekerjaan sampingan. Hal ini di karenakan pendapatan dari pekerjaan utama belum mampu mencukupi kebutuhan sehari-hari sehingga masyarakat harus mencari pekerjaan sampingan lainnya.

Tabel 6. Jenis Pekerjaan Sampingan Perambah

\begin{tabular}{llcc}
\hline No & \multicolumn{1}{c}{$\begin{array}{c}\text { Jenis pekerjaan sampingan } \\
\text { (di dalam kawasan Hutan) }\end{array}$} & $\begin{array}{c}\text { Jumlah per- } \\
\text { ambah (KK) }\end{array}$ & $\begin{array}{c}\text { Persentase per- } \\
\text { ambah }(\%)\end{array}$ \\
\hline 1. & Buruh harian & 38 & 39.58 \\
2. & Buruh tani dan ojek & 7 & 07.29 \\
3. & Buruh harian dan peternak & 10 & 10.42 \\
4. & Berdagang & 8 & 08.33 \\
5. & Pengrajin & 4 & 04,17 \\
6. & Bengkel & 3 & 03,13 \\
7. & Tidak Memiliki Pekerjaan Sampingan & 26 & 27,08 \\
\hline \multicolumn{2}{r}{ Jumlah } \\
\hline
\end{tabular}

Tabel 7. Pendapatan Total Perambah Hutan Produksi Air Sambat Reg. 84

\begin{tabular}{llccc}
\hline No & \multicolumn{1}{c}{ Sumber Pendapatan } & $\begin{array}{c}\text { Luas } \\
(\mathrm{Ha})\end{array}$ & $\begin{array}{c}\text { Pendapatan } \\
(\mathrm{Rp})\end{array}$ & $\begin{array}{c}\text { Persentase } \\
(\%)\end{array}$ \\
\hline 1 & Pertanian dalam hutan produksi & 150 & 1.671 .525 .000 & 99,29 \\
2 & Pertanian luar hutan produksi & 2 & 9.409 .600 & 00,56 \\
3 & Hasil sampingan & - & 2.500 .000 & 00,15 \\
\hline & Jumlah & 152 & 1.683 .434 .600 & 100 \\
\hline
\end{tabular}

Tabel 8. Status kesejahteraan responden berdasarkan tingkat pendapatan

\begin{tabular}{|c|c|c|c|c|}
\hline No & $\begin{array}{c}\text { Batas pendapatan / } \\
\text { kapita/tahun } \\
(\mathrm{Rp})\end{array}$ & Kategori & $\begin{array}{c}\text { Jumlah } \\
\text { perambah } \\
(\mathrm{KK}) \\
\end{array}$ & $\begin{array}{c}\text { Persentase } \\
(\%)\end{array}$ \\
\hline 1. & $<4.466 .052$ & Tidak sejahtera & 28 & 50,00 \\
\hline 2. & $4.466 .052-8.932 .104$ & Kurang Sejahtera & 21 & 37,5 \\
\hline 3. & $8.932 .104-17.864 .208$ & Sejahtera & 7 & 12,5 \\
\hline 4. & $>17.864 .208$ & Sangat sejahtera & 0 & 0 \\
\hline \multicolumn{3}{|c|}{ Jumlah } & 56 & 100 \\
\hline
\end{tabular}




\section{Strategi Pengelolaan Hutan Produksi Air Sambat Reg. 84}

Berdasarkan analisis diatas, dapat dirumuskan arahan dan strategi pengelolaan Hutan Produksi Air Sambat Reg.84 yaitu : 1). Skema Perhutanan Sosial, skema yang dapat diterapkan dalam program perhutanan sosial di Kawasan Hutan Produksi Air Sambat Reg. 84 ini adalah Hutan Hutan Kemasyarakatan $(\mathrm{HKm})$ seluas $\pm 963 \mathrm{Ha}$. Hutan Kemasyarakatan adalah hutan negara yang mana pengelolaannya dilakukan oleh masyarakat dengan tujuan untuk memberdayakan masyarakat sekitar agar tercipta kesejahteraan, 2). Tanah Obyek Reforma Agraria (TORA), sebagian Kawasan Hutan Produksi Air Sambat Reg.84 dapat diusulkan program TORA ini yaitu terhadap pemukiman penduduk (lahan pekarangan), fasilitas umum (jalan dan jembatan) yang telah dibangun masyarakat secara swadaya seluas $\pm 90,25$ Ha. Selain itu, faktor pendukung untuk kebijakan TORA pada kawasan ini adalah telah terbitnya Izin Pinjam Pakai Kawasan Hutan Untuk Pembangunan Jalan menuju SD Negeri 14 Maje.

\section{KESIMPULAN}

1. Tutupan lahan yang ada di Hutan Produksi Air Sambat berdasarkan hasil survei dan analisis spasial dikelompokkan menjadi lima kategori, yaitu hutan sekunder, pertanian lahan kering campur, tubuh air, lahan kosong, sawah dan pemukiman.

2. Kondisi Sosial Ekonomi perambah di Hutan Produksi Air Sambat Kabupaten Kaur sebagai berikut : hasil pengamatan menunjukkan bahwa daerah asal perambah $55.50 \%$ berasal dari desa-desa sekitar hutan produksi, $57.29 \%$ asal lahan rambahan diperoleh dengan cara membuka lahan sendiri, dengan motivasi merambah $46.88 \%$ dilatar belakangi oleh faktor ekonomi. Pendapatan total rumah tangga perambah dari lahan rambahan ratarata Rp. 11.607.812,50/tahun. Jika dilihat dari tingkat kesejahteraan ratarata perambah berada pada kategori cukup sejahtera.

3. Laju perubahan tutupan lahan yang mengalami peningkatan luas wilayah dalam jumlah yang paling besar adalah pertanian lahan kering campur. Tutupan lahan pertanian lahan kering campur mengalami peningkatan pada tahun 2015 sebesar 1.264,55 hektar atau $264.55 \%$ lebih luas dibandingkan dengan tahun 2009. Sedangkan tutupan lahan hutan sekunder mengalami penurunan luas wilayah sebesar $1.268,80$ hektar atau $35.36 \%$ dari luas tahun 2009.

4. Strategi pengelolaan yang sesuai di dalam kawasan Hutan Produksi Air Sambat adalah Perhutanan Sosial melalui Program Hutan kemasyarakatan seluas $\pm 963 \mathrm{Ha}$ dan untuk kawasan permukiman melalui program Tanah Obyek Reforma Agraria seluas $\pm 90,25 \mathrm{Ha}$.

\section{DAFTAR PUSTAKA}

Arief, Arifin .2001. Hutan dan Kehutanan. Kanisius. Yokyakarta.

Batubara, R.M.S. 2003. Hubungan Antar Kegiatan Perambahan Hutan Oleh Masyarakat Pendatang Dengan Kondisi Sosial Ekonomi Di Kawasan Ekosistem Leuser (KEL) (Studi Kasus Di Kecamatan Sei Lepan dan Kecamatan Besitang Kabupaten Langat Sumatera Utara. Medan : Thesis Program Pasca Sarjana. Universitas Sumatera Utara. (tidak dipublikasikan).

Departemen Kehutanan RI. Keputusan Menteri Kehutanan dan Perkebunan Nomor : 487/KPTS-II/1998 tanggal 27 Februari 1998 tentang Penetapan 
Kelompok Hutan Produksi Air Sambat Reg. 84 Seluas 1.938,00 (seribu Sembilan ratus tiga puluh delapan) Hektar yang Terletak di Daerah Tingkat II Bengkulu Selatan, Propinsi DATI 1 Bengkulu, Sebagai Kawasan Hutan Dengan Fungsi Hutan Produksi Tetap.

Effendi, Rachman, Indah Bangsawan, and Muhammad Zahrul M. 2007. Kajian pola-pola pemberdayaan masyarakat sekitar hutan produksi dalam mencegah illegal logging. Jurnal Penelitian Sosial dan Ekonomi Kehutanan Vol. 4 No. 4 Desember 2007.

Gautama, Iswara. 2007. Studi Sosial Ekonomi Masyarakat Pada Sistem Agroferestry Di Desa Lasiwala Kabupaten Sidrap. Jurnal Hutan dan Masyarakat, 2(3):319-328.

Kasim, B. 1990. Hubungan Kondisi Sosial Ekonomi Masyarakat Pemukiman Liar Terhadap Tingkat Pemggunaan Lahan di Taman Nasional Ujung Kulon. Jurusan Konservasi Sumberdaya Hutan Fakultas Kehutanan Institut Pertanian Bogor. Bogor.
Kementerian Lingkungan Hidup dan Kehutanan Republik Indonesia, 2017. Surat Keputusan Menteri Lingkungan Hidup dan Kehutanan Republik Indonesia Nomor: SK.4865/MENLHKPKTL/REN/PLA.0/9/2017 tentang Peta Indikatif dan Areal Perhutanan Sosial,

Lillesand TM, Kiefer FW. 2003. Penginderaan Jauh dan Implementasi Citra. Alih bahasa. R. Dubahri. Yokyakarta : Gajah Mada University Press.

Senoaji G. 2011. Kondisi Sosial Ekonomi Masyarakat Sekitar Hutan Lindung Bukit Daun Di Bengkulu. Bengkulu : Jurnal Penelitian Jurusan Kehutanan Fakultas Pertanian, Volume 13 No. 1, Maret 2011 : 1-17.

Sylviani, 2008. Kajian Dampak Perubahan Fungsi Kawasan Hutan Terhadap Masyarakat Sekitar. Jurnal Penelitian Sosial dan Ekonomi Kehutanan Vol. 5 No. 3 September 2008 